\title{
Hybridisation and chloroplast capture between ancient Themeda triandra ecotypes in Australia
}

Luke T. Dunning ${ }^{1 *}$, Jill K. Oloffson², Alexander S.T. Papadopulos ${ }^{3}$, Paulo C. Baleeiro ${ }^{4}$, Sinethemba Ntshangase ${ }^{5}$, Nigel Barker ${ }^{5}$, Richard W. Jobson ${ }^{6}$

\section{Affiliations}

${ }^{1}$ Ecology and Evolutionary Biology, School of Biosciences, University of Sheffield, Western Bank, Sheffield S10 2TN, United Kingdom.

${ }^{2}$ Section for Forest, Nature and Biomass, Department of Geosciences and Natural Resource Management, University of Copenhagen, Rolighedsvej 23, 1958 Frederiksberg C, Denmark. ${ }^{3}$ Molecular Ecology and Evolution, Bangor University, Environment Centre for Wales, Deiniol Road, Bangor, LL57 2UW, United Kingdom.

${ }^{4}$ Department of Biological Science, The University of Queensland, St Lucia, Qld 4076, Australia.

${ }^{5}$ Department of Plant and Soil Sciences, University of Pretoria, Hatfield 0028, South Africa ${ }^{6}$ National Herbarium of New South Wales, Royal Botanic Garden, Sydney, Mrs Macquaries Road, Sydney, NSW 2000, Australia.

*Corresponding author: Luke T. Dunning; Ecology and Evolutionary Biology, School of Biosciences, University of Sheffield, Western Bank, Sheffield S10 2TN, United Kingdom; +44 (0) 1142220027; I.dunning@sheffield.ac.uk 


\section{Abstract}

Ecotypes are distinct populations within a species which are adapted to specific environmental conditions. Understanding how these ecotypes become established, and how they interact when reunited, is fundamental to elucidating how ecological adaptations are maintained. This study focuses on Themeda triandra, a dominant grassland species across Asia, Africa and Australia. It is the most widespread plant in Australia, where it has distinct ecotypes that are usually restricted to either wetter and cooler coastal regions or the drier and hotter interior. We use whole genome sequencing for over 80 Themeda accessions to reconstruct the evolutionary history of $T$. triandra and related taxa. A chloroplast phylogeny confirms that Australia was colonised by T. triandra twice, with the division between ecotypes predating their arrival in Australia. The nuclear genome provides evidence of gene-flow among the ecotypes, largely restricted to two geographic areas. In northern Queensland there appears to be a hybrid zone with admixed nuclear genomes and shared plastid haplotypes. Conversely, in the cracking claypans of Western Australia, there is cytonuclear discordance with individuals possessing the coastal plastid and interior clade nuclear genomes. This chloroplast capture is potentially a result of adaptive introgression, with selection detected in the rpoC2 gene which is associated with water use efficiency. A stable hybrid zone in the east, and the displacement of one ecotype in the west, highlights the unpredictable nature of hybrid zones, with repeated contacts between the same ecotypes producing different outcomes. 


\section{[1] Introduction}

Understanding why some species are found in a broad range of environments whilst others are restricted to particular habitats is one of the fundamental questions in evolutionary biology. Widely distributed species are typically able to tolerate multiple environmental conditions, either through extensive phenotypic plasticity or specialised ecotype differentiation (Stamp \& Hadfield, 2020). It is increasingly clear that locally adapted ecotypes can evolve multiple times in response to the same selection pressures (Jones et al., 2012; Ostevik et al., 2012; Butlin et al., 2014), and that this can happen over very short timescales (Papadopulos et al., 2021). The mechanisms that a particular species utilises are dependent on numerous factors including the levels of gene flow, the extent of standing genetic variation and the scale of environmental heterogeneity (Via \& Lande, 1985). Ecotypes typically arise when there is some reduced gene flow as a result of geographic isolation and strong environmental selection pressure. Determining how ecotypes interact when they come into secondary contact is important for our understanding of local adaptation and ultimately speciation (Nosil 2012).

Themeda triandra is one of the most widely distributed $\mathrm{C}_{4}$ grass species in the world (Sage, 2017). It has a relatively recent evolutionary origin, originating c. $1.5 \mathrm{Ma}$, most likely in Asia (Dunning et al., 2017). T. triandra has rapidly spread across Asia, Africa and Australia where it is found across a range of climates (Snyman et al., 2013). It is a dominant grassland species with significant ecological and economic importance (Snyman et al., 2013). It is a morphologically diverse species, and several potential taxonomic synonyms exist (Arthan et al., 2021). These synonyms range from regional varieties with restricted distributions to the globally invasive Themeda quadrivalvis (Arthan et al., 2021).

In Australia, $T$ triandra is known to have two predominant ecotypes which are thought to be a result of ploidy differences (Godfree et al., 2017). The coastal ecotype is diploid and generally grows in cooler and wetter climates, and the inland form is prominently tetraploid and survives in drier and hotter environments (Godfree et al., 2017). Experimental manipulations show that under drought and heat stress the inland ecotype produces up to four times as much seed (Godfree et al., 2017), with elevated fitness attributed to its increased genome size. This conclusion has been supported by recent work that confirms ploidy may facilitate adaptation to hotter climates and it should be considered in adaptive management strategies (Ahrens et al., 2020). However, both of these studies based their 
conclusions on the assumption that the inland ecotype is derived from the coastal form, and these ploidy and ecological differences are not more ancient, predating the colonisation of Australia. Recent phylogenetic studies have highlighted that Australia may have been colonised by T. triandra multiple times (Dunning et al., 2017), but it is not yet clear how these colonisations are related to the different ecotypes.

In this study we use whole genome sequencing from over 80 Themeda accessions to reconstruct the evolutionary history of Themeda triandra in Australia. We specifically aim to test whether the two Australian ecotypes evolved rapidly following colonisation, potentially due to auto-polyploidisation, or alternatively, the ecotypes arrived in Australia independently with no recent auto-polyploidy event. Our results show that considering a broader evolutionary history rather than focusing purely on local diversity is essential to elucidate the mechanism of rapid environmental adaptation in widely distributed species. 


\section{[2] Materials and Methods}

\section{[2.1] Sampling and whole-genome sequencing}

An initial Australia wide survey was conducted using an ITS/ETS barcode to assess the diversity within T. triandra / T. quadrivalvis clade. In total, we collected 332 accessions and extracted DNA, amplified the target region and generated a maximum parsimony phylogenetic tree as in Jobson et al. (2017). We then selected 64 ingroup samples distributed across this tree (Figure S1) and three outgroup samples for whole genome sequencing. The 67 selected Themeda accessions were then sent for sequencing at the Ramaciotti Centre for Genomics (Sydney, Australia). Libraries were constructed using the Illumina DNA Prep kit and sequenced on a single Illumina NovSeq 6000 2x150bp flow cell. Estimated genome coverage for each sample was calculated using a $1 \mathrm{C}$ value of $1.05 \mathrm{Gbp}$ (50\% of the mean tetraploid (4n) T. triandra 1C value; Estep et al., 2014).

\section{[2.2] Chloroplast genome assembly and phylogenetics}

Chloroplast genomes were assembled from the raw whole-genome sequencing data using NOVOPlasty v.4.2.1 (Dierckxsens et al., 2017) with default parameters and a matK seed alignment extracted from a chloroplast genome of a closely related species (Andropogoneae: Heteropogon sp., GenBank accession: KY707768.1). The resulting contig options were aligned to pre-existing T. triandra and T. quadrivalvis chloroplast assemblies from NCBI genbank using MAFFT v.7017 (Katoh et al., 2002), and manually rearranged using Geneious v.5.3.6 (Kearse et al., 2012) if required. If the chloroplast assembly was incomplete, the process was repeated using a different seed alignment (the $r b c L$ gene or the entire chloroplast sequence from the same Heteropogon sp. accession). The inverted repeat region was then removed from the alignment and a maximum-likelihood phylogenetic tree with 100 bootstrap replicates inferred using PhyML v.20120412 (Guindon et al., 2010), with the best-fit nucleotide substitution model selected with SMS v.1.8.1 (Lefort et al., 2017).

\section{[2.3] Nuclear marker assembly and phylogenetics}

We used a reference-based approach to generate consensus sequences for single-copy nuclear genes (Olofsson et al., 2016; Dunning et al., 2019; Olofsson et al., 2019). There is no published genome for any Themeda species and we therefore used a non-specific reference genome from the same grass tribe (Andropogoneae: Sorghum bicolor, GenBank accession: GCA_000003195.3; McCormick et al., 2018). Our analysis focused on the Benchmarking Universal Single-Copy Orthologs (BUSCO; Simão et al., 2015) in the 
poales_odb10 database present in the S. bicolor genome. This was determined using Blastp v.2.8.1+ to identify S. bicolor proteins with a $100 \%$ sequence similarity match of at least 100 amino acids long to a sequence in the poales_odb10 database ( $n=3,386$ genes; n.b. a strict similarity cut-off was used as the poales_odb10 database includes S. bicolor proteins).

The 67 Themeda samples sequenced here were supplemented with $14 T$. triandra and $T$. quadrivalvis data sets retrieved from the NCBI Sequence Read Archive (SRA; Burke et al., 2016; Dunning et al., 2017; Arthan et al., 2021). Prior to mapping the Themeda sequencing data to the S. bicolor genome, the data was cleaned using Trimmomatic v.0.38 (Bolger et al., 2014) to remove adaptor contamination, low quality bases (4 bp sliding window with mean Phred score < 20) and short reads (<50 bp). NGSQC Toolkit v. 2.3.3 (Patel \& Jain, 2012) was then used to discard reads where $80 \%$ of the sequence had a Phred score $<20$ or the read contained an ambiguous base. Finally, PRINSEQ v.0.20.3 (Schmieder \& Edwards, 2011) was used to remove duplicated reads. The cleaned data was then mapped to the $S$. bicolor reference genome using Bowtie2 v.2.3.4.3 (Langmead \& Salzberg, 2012) with default parameters. Consensus sequences for each Themeda sample were then generated from the short-read alignment for each single-copy gene in the $S$. bicolor genome using previously described methods for low-coverage whole-genome data (Olofsson et al., 2016; Dunning et al., 2019; Olofsson et al., 2019). Each individual gene alignment was subsequently trimmed with trimAl v.1.2rev59 (Capella-Gutiérrez et al., 2009) using the -automated1 option which optimises alignment trimming for maximum-likelihood phylogenetic tree reconstruction. Short sequences (< $200 \mathrm{bp}$ ) were discarded from the trimmed alignment, and entire gene alignments were discarded if it was either $<500 \mathrm{bp}$ or did not include all samples $(n=1,286$ genes retained).

A maximum-likelihood tree was inferred from a concatenated nuclear alignment of all 1,286 genes (alignment length $=2,532,106$ bp) using IQ-TREE v.1.6.12 (Nguyen et al., 2015) with 1,000 ultrafast bootstrap replicates. Individual gene trees were also generated using SMS and PhyML as described above. A DensiTree v.2.2.7 (Bouckaert, 2010) plot was made by overlaying the individual gene trees that had been transformed to be ultrametic using the chronopl function (lambda $=1$ ) as part of the ape v.5.2 (Paradis \& Schliep, 2019) package in $R$ v.3.4.3. A coalescence species tree was generated from the individual gene trees using ASTRAL v.5.7.5 (Zhang et al., 2018) after collapsing branches with $<10 \%$ bootstrap support using Newick utilities v.1.6 (Junier \& Zdobnov, 2010). Phyparts v.0.0.1 (Smith et al., 2015) was used to evaluate individual gene tree support for the coalescence species tree. The 
results were visualised using the phypartspiecharts.py python script written by M. Johnson (available from: https://github.com/mossmatters/phyloscripts/blob/master/phypartspiecharts).

\section{[2.3] Population structure}

Genotype likelihoods were estimated across the nuclear genome of the 81 Themeda acessions (67 sequenced here) using ANGSD v.0.929-13-gb5c4df3 (Korneliussen et al., 2014) and the bowtie2 alignments generated above. Mapped reads and bases with a quality $<20$ were discarded, a per-individual maximum depth of 20 was used, and sites had to be present in at least two individuals to be considered. A principal component analysis (PCA) of the genotype likelihoods was generated using PCAngsd v.0.973 (Meisner \& Albrechtsen, 2018) to estimate a covariance matrix before plotting the results in $R$ with eigenvector decomposition. The number of genetic clusters $(K)$ in the genotype likelihoods was examined using NGSadmix (Skotte et al., 2013), with default parameters and 10 replicates for $\mathrm{K}$ between 1 and 10 . The optimal $\mathrm{K}$ was determined using the $\Delta \mathrm{K}$ method (Evanno et al., 2005) implemented using CLUMPAK (Kopelman et al., 2015). PCA plots and the admixture analysis were repeated for only the Australian T. triandra samples using default parameters. Pairwise $F_{\mathrm{ST}}$ was estimated using ANGSD among Australian populations restricted to individuals that had $99 \%$ of the genomes assigned to a single genetic cluster both globally and using a sliding window method (window $=50 \mathrm{~kb}$, slide $=10 \mathrm{~kb}$ ).

\section{[2.4] Estimating ploidy}

The ploidy of each sample was estimated using HMMploidy (Soraggi et al., 2021), a method which has been developed to infer ploidy from low-depth sequencing data. A multi-sample mpileup file was generated for HMMploidy from the bowtie2 alignments with SAMtools v.1.9 (Li et al., 2009), only including reads with a minimum read mapping quality (mapQ) of 20 , counting anomalous read pairs and setting a maximum per-file depth of 25 . Genotype likelihoods were generated using HMMploidy with default parameters, which calculates likelihoods for a range of ploidy levels (1n-6n). Ploidy levels were then inferred in $100 \mathrm{~kb}$ windows across the $S$. bicolor reference genome, with a minimum number of two individuals per locus to be considered. The percentage of $100 \mathrm{~kb}$ windows supporting each ploidy level was then calculated, ignoring those that were inferred to be haploid. Samples were arbitrarily assigned to a single ploidy if it was supported by over $50 \%$ of windows, or 'likely' a certain ploidy if only one category was supported by over $40 \%$ of windows. If samples were not assigned to a single ploidy level, but over $60 \%$ of windows supported a ploidy level greater than diploid, then they were classified as 'likely polyploid', or 'unknown' if less than $60 \%$. 


\section{[2.4] Inferring positive selection}

Pairwise estimation of the ratio $(\omega)$ of synonymous (dS) and non-synonymous (dN) substitutions between sequences was calculated using the Yang and Nielson (2000) method implemented in yn00, distributed as part of the paml v.4.9j package (Yang, 2007). Site (M1a and $\mathrm{M} 2 \mathrm{a}$ ) and branch-site models (BSA and BSA1) models to infer if a gene was evolving under significant positive selection were implemented in codeml, distributed as part of the paml v.4.9j package (Yang, 2007). For these models we used the topology of the whole chloroplast genome tree (Figure $1 \&$ S1). 


\section{[3] Results}

\section{[3.1] Phylogenetic relationships inferred from the chloroplast.}

As part of this study we generated over $600 \mathrm{~Gb}$ (mean $=4.6 \mathrm{~Gb}, \mathrm{SD}=1.4 \mathrm{~Gb}$ per sample) of whole-genome sequencing data for 67 Themeda accessions, with an emphasis on sampling T. triandra (and potential taxonomic synonyms) from across its range in Australia ( $n=61$; Figure 1 \& S2). These data were used to assemble whole chloroplast genomes, before being aligned with previously published assemblies $(n=15)$. Inferring the phylogenetic relationships based on the chloroplast genomes (82 accessions in total, 118,550 bp alignment, $95.4 \%$ identical sites, $97.9 \%$ within T. triandra; $98.6 \%$ and $99.1 \%$ when excluding indels) shows that $T$. triandra is not monophyletic, with $T$. quadrivalvis nested within. The phylogeny also shows that the Australian samples do not form a single clade (Figure 1), as would be expected if there was a single colonisation of Australia. The two large Australian clades (Clade I \& II) are well supported, each sister to Asian accessions. Clade I comprises the coastal T. triandra accessions predominantly from wetter environments (in green) and those from the Pilbara cracking claypans in Western Australia (in blue; Figure 1). Clade II is composed of the western T. triandra form (in yellow), which are predominantly from dryer habitats in the Australian interior. When comparing the coastal (green) and claypan (blue) $T$. triandra accessions from Clade I with the western Australia form from Clade II (yellow), there are 48 and 64 fixed biallelic SNPs respectively. Within Clade I there are 13 fixed biallelic SNPs separating the coastal (green) and Pilbara (blue) T. triandra accessions.

\section{[3.2] Phylogenetic relationships inferred from the nuclear genome.}

The nuclear dataset was generated by mapping the short-read data from 81 Themeda accessions to the $S$. bicolor genome. Using a non-specific reference reduces the proportion of data that maps (mean $=10.64 \%, S D=1.35 \%$ ), with valid alignments mainly restricted to exons (Olofsson et al., 2019). The nuclear relationships were inferred using data from 1,286 single-copy genes with a combined alignment length of 2,532,106 bp. The concatenated maximum-likelihood tree and the coalescent species tree both support $T$. triandra as being monophyletic, sister to T. quadrivalvis (Figure 2, S3-S5). In the nuclear phylogeny the Australian T. triandra accessions are monophyletic, and within this group the two distinct clades identified in the chloroplast phylogeny are recapitulated with a few exceptions. Most notably is the Pilbara clade which is identified as Clade I based on the chloroplast (in blue; Figure 1), but is nested deep within Clade II based on the nuclear genome (Figure 2). There 
are also two accessions from Far North Queensland (FNQ) which are part of Clade II in the chloroplast genome which are nested within Clade I based on the nuclear genome, where they form a clade with other accessions from FNQ. Evaluating the individual gene tree support for the nuclear topology shows that many of the nodes are poorly supported beyond delimiting the main clades (Fig 2 \& S5). This lack of gene-tree support for the species tree topology can be a result of incomplete lineage sorting, hybridisation and/or a lack of genetic variation.

\section{[3.3] Genetic variations and structure within Themeda.}

The principle component analysis largely recovered the nuclear phylogeny groupings (Figure $3 \mathrm{~A}$ ). The first principal component axis explains $27.0 \%$ of the variation in the data and predominantly splits the $T$. triandra samples from the other accessions, although they themselves are clustered in their nuclear phylogeny clades. The second principal component explains $16 \%$ of the variation in the data and splits the Australian accession into the two distinct nuclear clades, with a small group of five accessions from FNQ and the surrounding area. The dominance of Australian T. triandra accessions in the PCA is likely to be a direct result of the high proportion $(79.0 \%)$ of samples these accessions comprise. We therefore repeated the analysis, only including Australian T. triandra accessions, with similar results (Figure S6).

The optimal number of genetic clusters $(K)$ based on the admixture analysis is three, with a secondary optimum of four (Fig $3 B \& C$ ). For both $K=3$ and $K=4$ the accessions outside of the Australian T. triandra are lumped into a single isolated group, although the $T$. triandra accession from China has between 10 and $20 \%$ of its genome assigned to one of the other genetic clusters (Figure 3D). The most optimal $K(3)$ largely recovers the nuclear phylogeny, confirming that the Pilbara claypan accessions have a mis-match between their chloroplast (Clade I) and nuclear (Clade II) genomes. The samples are ordered from west to east in each chloroplast genotype block, indicating that there is increased admixture where the two clades come into contact (Figure 3D). There is an extremely high-degree of admixture in five individuals with roughly equal proportions of their nuclear genome assigned to Clade I and Clade II (Figure 3D). These are the same five individuals from FNQ and the surrounding area which were intermediate in the PCA (Figure 3A). These individuals also make up the small nuclear clade with mixed chloroplast genotypes in Figure 2. The secondary optimum $K$ $=4$ recovers the same pattern, although it largely assigns individuals with visible admixture in $K=3$ to an additional 4 th genetic group (Figure 3D). The same groupings are largely 
recaptured when repeating the PCA and admixture analysis (optimum $K=3$; secondary optimum $K=2$ ) with only Australian $T$. triandra samples (Figure S5). With this reduced sample set PC1 accounts for $26 \%$ of variation and has a significant correlation with sample longitude (Pearson's $r=0.84 ;$ P-value $<0.001$ ).

Pairwise $F_{\mathrm{ST}}$ confirmed that the nuclear genome of the claypan form and inland ecotype are more similar $\left(F_{\mathrm{ST}}\right.$ unweighted $=0.06 ; F_{\mathrm{ST}}$ weighted $\left.=0.19\right)$ to each other than to the coastal ecotype $\left(F_{\mathrm{ST}}\right.$ unweighted $=0.22 ; F_{\mathrm{ST}}$ weighted $=0.72 ;$ and $F_{\mathrm{ST}}$ unweighted $=0.18 ; F_{\mathrm{ST}}$ weighted $=0.70$, respectively). Pairwise $F_{\mathrm{ST}}$ across the genome showed a similar pattern (Figure S7).

\section{[3.4] Polyploidy is restricted to the inland ecotype.}

All outgroups and accessions of the Australian coastal ecotype were assigned as diploid, or likely diploid (Table S2). Accessions from the interior ecotype were inferred to have a range of ploidies ranging from diploid to hexaploid, although a majority $(66 \%)$ of samples were polyploids (Table S2). No sample from this clade was assigned as tetraploid, even though sampling in southeastern Australia indicated this is the most common ploidy for the inland ecotype (Godfree et al., 2017; Ahrens et al., 2020). It is likely that in our analysis tetraploid individuals were assigned to the 'likely polyploid' category in our results. The introgressed individuals of both ecotypes from FNQ were diploid, indicating that these were not allopolyploids and likely represent early-generation hybrids. The ploidy assignments were largely consistent across the different chromosomes, with some differences potentially a result of aneuploidy which has been documented in Australian individuals (Hayman, 1960).

\section{[3.5] Positive selection in a single chloroplast gene.}

We looked at sequence variation within all 75 protein coding chloroplast genes to detect signs of positive selection between the two Australian T. triandra clades potentially involved in a chloroplast capture scenario (i.e. blue and yellow clades; Figure 1). Out of the 75 genes, 60 had no fixed differences, 11 had fixed differences but they were all synonymous mutations, and four ( $n d h f, r p / 22, r p o A$, and rpoC2) contained non-synonymous mutations. Only rpoC2 had more than three fixed differences and was therefore used for positive selection analysis. A simple pairwise comparison between sequences using the Yang and Nielsen (2000) method indicates rpoC2 had been under positive selection between the Australian clades, with an excess of non-synonymous mutations $(\omega=1.39$; $d N=0.0012$; $d S$ $=0.0009)$. This conclusion is supported when testing for positive selection using more 
complex site models across the phylogeny (M2a $>$ M1a; $P$-value $<0.001)$, which identified one site with $>95 \%$ probability as being under positive selection (site $1503 ; \mathrm{P}=98.9 \%$ ). The amino acid residue at this site is divergent between the clades of interest as a result of a non-synonymous mutation that has arisen on the branch separating the Chinese/Australian Clade II samples from the Tanzanian accession (Figure 1). However, branch-site models did not find any significant evidence for elevated positive selection on the branches separating the two clades of interest compared to the rest of the tree (Table S3). 


\section{[4] Discussion}

Themeda triandra is one of the most charismatic tropical grass species. Despite being relatively young (Dunning et al., 2017), this species has become dominant in many African, Asian and Australian grasslands, and has even been dubbed the 'The food of the Serengeti grazers' (Sage, 2017). It is the most widely distributed plant species in Australia (Gallagher 2016) with two predominant ecotypes largely restricted to the wetter, cooler coastal regions or the drier, hotter interior. It is therefore a great model system to investigate rapid environmental adaptation. Here, we use whole-genome sequencing from over 80 Themeda accessions to show that divergence between the ecotypes pre-dates the colonisation of Australia by $T$. triandra, and they are therefore not a result of a recent auto-polyploidisation event. We also show extensive gene-flow between ecotypes with varying outcomes.

\section{[4.1] Ecotypes predate the colonisation of Australia}

This study confirms previous findings that Australia was colonised at least twice by Themeda triandra (Dunning et al., 2017). Interestingly, these independent colonisations actually represent the arrival of the two different ecotypes, one that inhabits the cooler and wetter coastal regions and the other that is found in the hotter and drier Australian interior (Figure 1). Previous studies have concluded that the differences between these ecotypes can be attributed to recent polyploidy events (Godfree et al., 2017; Ahrens et al., 2020). While our results support these previous conclusions that ecotypes do largely segregate by ploidy level (Table S2), the adaptation to these different environments likely pre-dates the colonisation of Australia and is not solely the result of a recent auto-polyploidisation event. Indeed, we detect diploid individuals within the dryland interior ecotype. Therefore, to understand the colonisation of the dryland Australian interior it is essential to consider the ecotype's original diversification in Asia. A recent study of $T$. triandra in Yunnan-Guizhou Plateau in southwest China also found distinct cool- and warm-adapted lineages that are at least 2 million years old (Chu et al., 2021). However, the distinct Chinese populations are unlikely to be the source of the two Australian ecotypes as the Chinese samples form a monophyletic group based on chloroplast markers, although this is based on a reduced set of markers and a topology with relatively low support (Chu et al., 2021).

Themeda triandra is also widespread in Africa, and grows in a wide range of climatic regions and exhibits similar diversity in ploidy levels (Snyman et al., 2013). Although presently not possible, it would be interesting to compare the Australian results with a similar study in 
Africa. Potentially the African continent was also colonised by multiple ecotypes, and indeed African accessions have a similar phylogenetic pattern being paraphyletic for the chloroplast genome (placement of Tanzanian accession, Fig. 1) and monophyletic for the nuclear genome (Fig. 2). Comparison between Australia and Africa will ultimately show if the broad climatic niche $T$. triandra inhabits on both continents is attributed to ancestral genetic variation or rapid convergent evolution.

\section{[4.2] Hybridisation between ecotypes.}

The nuclear phylogenies and population genomics results indicate that there is ongoing gene flow between the ecotypes where they come into contact (Figure $2 \& 3$ ). The highest levels of introgression is localised to Far North Queensland (FNQ) where diploid accessions of both ecotypes are found in close proximity and which have the appearance of early generation hybrids (Figure 2). Populations at increasing distance from this potential hybrid zone contain successively reduced introgression to populations with a relatively pure nuclear background for each ecotype. Themeda triandra only relatively recently colonised Australia (<1.3 Mya; Dunning et al., 2017) and at present it is unclear how stable this hybrid zone in Far North Queensland is, and it may represent a profitable geographic location to investigate the genetic basis of the two ecotypes. It is also likely that the predominant ploidy differences between ecotypes also aids in maintaining the divergence between ecotypes (Olofsson et al., 2021)

There is also potentially ongoing gene-flow from Asia into northern Australia. When including all accessions in the structure analysis the Chinese sample shares noticeably high levels of population assignment to the Australian samples from northern Australia, and at $k=4$ these regions separate into their own 4th cluster (Figure 3 ). This might also explain why when restricting the analysis to only Australian accessions $k=3$ remains the optimal number of populations as it is still detecting the signal of introgression into these accessions. Further sampling, particularly in Southeast Asia, is required to confirm this conclusion.

\section{[4.3] Chloroplast capture in cracking claypans of Western Australia}

The Western Australian cracking claypans around Pilbara are characterised by frequent inundation with fresh water, compared to the surrounding drier desert regions. Themeda triandra accessions in these restricted habitats have been previously classified as a separate species (Themeda sp. Hamersley Station) based on morphological differences, although subsequent inspection by taxonomists have shown these differences are largely qualitative. 
The genetic data indicate that populations from these areas are in fact Themeda triandra (Figure 1 \& 2). However, there is clear nuclear \& chloroplast discordance in these accessions, possessing an interior ecotype nuclear genome and a coastal ecotype chloroplast. A comparison of the coding genes in the chloroplast indicates that one gene (rpoC2) in particular has an $\omega>1$ indicating positive selection between ecotypes. This may mean that the observed chloroplast capture was a result of adaptive introgression.

The rpoC2 gene encodes a DNA-dependent RNA polymerase, and its expression has been previously associated with increased water use efficiency in the common bean (Phaseolus vulgaris; Ruiz-Nieto et al., 2015). Comparative analysis of rice chloroplast genomes have also shown rpoC2 to be under positive selection in Oryza species from high light environments, and in particular Oryza autraliensis, a wild rice native to northern Australia (Gao et al., 2019). However, when attempting to determine if the amino acid substitutions are convergent between $O$. autraliensis and $T$. triandra it became clear that the positive selection result in the former are a likely a false-positive driven by poorly aligned indel regions rather than actual amino acid substitutions. The role of $r p o C 2$ in water use efficiency, and the difference in water availability in the cracking claypans versus the surrounding habitat, potentially indicates that adaptive chloroplast capture of the coastal chloroplast has occurred. This pattern might also provide support for a once widespread coastal ecotype across Australia, including its interior, which has then been largely replaced by the interior ecotype as the continent oscillated in water availability before trending to become drier in the last 350,000 years (Kershaw et al., 2003).

\section{[4.4] Recent speciation of Themeda quadrivalvis}

Whether Themeda quadrivalvis is a synonym of Themeda triandra, or if it is a separate species has been debated for some time (Keir \& Vogler, 2006; Veldkamp et al., 2016; Dunning et al., 2017; Arthran et al., 2021). Themeda quadrivalvis is a globally distributed invasive weed and the only apparent fixed difference between species is that $T$. quadrivalvis is annual whereas $T$. triandra is perennial. This is the first study to sequence multiple genomes of $T$. quadrivalvis and the results support a previous conclusion that this species has only recently diverged from $T$. triandra. In the early stages of speciation, a daughter species would sit within the larger paraphyletic parental species (Pennington \& Lavin 2016). This is exactly what we observe in the slower evolving chloroplast genome (Figure 1), whereas each species is monophyletic in the nuclear genome (Figure 2). Despite occurring in the same geographic location within Australia, we fail to detect any meaningful gene flow 
between these putative species (Figure 3), suggesting that they are now largely reproductively isolated.

\section{[4.5] Conclusion}

Themeda triandra represents one of the most recent and successful rapid radiations of grasses. In a relatively short space of time, it has become the most broadly distributed plant species within Australia across a very broad ecological spectrum. This remarkable feat is likely due to ecological plasticity. However, this research shows that this ability to occupy almost every climatic niche in Australia is a result of independent colonisation of the continent by ecotypes within this species, with some further local adaptation potential arising following introgression of chloroplast haplotypes. This results highlights the importance of standing genetic variation within a species in facilitating rapid adaptation to a diverse array of habitats. 


\section{[5] Acknowledgements}

We thank Natalie Murdock and Hayden Ajduk (Rio Tinto Mining), Steven Dillon (PERTH), and Andrew Mitchell (Perth, WA) for help with images, fieldwork and identification of specimens. We are grateful for access to collections and provision of loans by managers and staff at AD, AK, BRI, CANB, CNS, DNA, HO, MEL, NSW, PERTH, SING. The Australian Biological Resource Study (ABRS) and Rio Tinto Mining provided funding for this research. LTD is supported by a Natural Environment Research Council Independent Research Fellowship (NE/T011025/1). 


\section{[6] References}

Ahrens, C. W., James, E. A., Miller, A. D., Scott, F., Aitken, N. C., Jones, A. W., ... \& Rymer, P. D. (2020). Spatial, climate and ploidy factors drive genomic diversity and resilience in the widespread grass Themeda triandra. Molecular Ecology, 29(20), 3872-3888.

Arthan, W., Dunning, L. T., Besnard, G., Manzi, S., Kellogg, E. A., Hackel, J., ... \& Vorontsova, M. S. (2021). Complex evolutionary history of two ecologically significant grass genera, Themeda and Heteropogon (Poaceae: Panicoideae: Andropogoneae). Botanical Journal of the Linnean Society.

Bolger, A. M., Lohse, M., \& Usadel, B. (2014). Trimmomatic: a flexible trimmer for Illumina sequence data. Bioinformatics, 30, 2114-2120.

Bouckaert, R. R. (2010). DensiTree: making sense of sets of phylogenetic trees. Bioinformatics, 26(10), 1372-1373.

Burke, S. V., Wysocki, W. P., Zuloaga, F. O., Craine, J. M., Pires, J. C., Edger, P. P., ... \& Duvall, M. R. (2016). Evolutionary relationships in Panicoid grasses based on plastome phylogenomics (Panicoideae; Poaceae). BMC Plant Biology, 16(1), 1-11.

Butlin, R. K., Saura, M., Charrier, G., Jackson, B., André, C., Caballero, A., ... \& Rolán-Alvarez, E. (2014). Parallel evolution of local adaptation and reproductive isolation in the face of gene flow. Evolution, 68(4), 935-949.

Capella-Gutiérrez, S., Silla-Martínez, J. M., \& Gabaldón, T. (2009). trimAl: a tool for automated alignment trimming in large-scale phylogenetic analyses. Bioinformatics, 25, 1972-1973.

Chu, Y., Wee, A. K., Lapuz, R. S., \& Tomlinson, K. W. (2021). Phylogeography of two widespread $\mathrm{C}_{4}$ grass species suggest tableland and valley grassy biome in southwestern China pre-date human modification. Global Ecology and Conservation, e01835. 
Dierckxsens, N., Mardulyn, P., \& Smits, G. (2017). NOVOPlasty: de novo assembly of organelle genomes from whole genome data. Nucleic acids research, 45, e18-e18.

Dunning, L. T., Liabot, A. L., Olofsson, J. K., Smith, E. K., Vorontsova, M. S., Besnard, G., ... \& Lehmann, C. E. (2017). The recent and rapid spread of Themeda triandra. Botany Letters, 164(4), 327-337.

Dunning, L. T., Olofsson, J. K., Parisod, C., Choudhury, R. R., Moreno-Villena, J. J., Yang, Y., ... \& Christin, P. A. (2019). Lateral transfers of large DNA fragments spread functional genes among grasses. Proceedings of the National Academy of Sciences, $116,4416-4425$.

Estep, M. C., McKain, M. R., Diaz, D. V., Zhong, J., Hodge, J. G., Hodkinson, T. R., ... \& Kellogg, E. A. (2014). Allopolyploidy, diversification, and the Miocene grassland expansion. Proceedings of the National Academy of Sciences, 111, 15149-15154.

Evanno, G., Regnaut, S., \& Goudet, J. (2005). Detecting the number of clusters of individuals using the software STRUCTURE: a simulation study. Molecular ecology, 14(8), 2611-2620.

Gao, L. Z., Liu, Y. L., Zhang, D., Li, W., Gao, J., Liu, Y., ... \& Eichler, E. E. (2019). Evolution of Oryza chloroplast genomes promoted adaptation to diverse ecological habitats. Communications biology, 2, 1-13.

Gallagher, R. V. (2016). Correlates of range size variation in the Australian seed-plant flora. Journal of Biogeography, 43(7), 1287-1298.

Guindon, S., Dufayard, J. F., Lefort, V., Anisimova, M., Hordijk, W., \& Gascuel, O. (2010). New algorithms and methods to estimate maximum-likelihood phylogenies: assessing the performance of PhyML 3.0. Systematic biology, 59, 307-321.

Godfree, R. C., Marshall, D. J., Young, A. G., Miller, C. H., \& Mathews, S. (2017). Empirical evidence of fixed and homeostatic patterns of polyploid advantage in a keystone grass exposed to drought and heat stress. Royal Society open science, 4(11), 170934. 
Hayman, D. L. (1960). The distribution and cytology of the chromosome races of Themeda australis in southern Australia. Australian Journal of Botany, 8(1), 58-68.

Jobson, R. W., Baleeiro, P. C., \& Reut, M. S. (2017). Molecular phylogeny of subgenus Polypompholyx (Utricularia; Lentibulariaceae) based on three plastid markers: diversification and proposal for a new section. Australian Systematic Botany, 30(3), 259-278.

Jones, F. C., Grabherr, M. G., Chan, Y. F., Russell, P., Mauceli, E., Johnson, J., ... \& Kingsley, D. M. (2012). The genomic basis of adaptive evolution in threespine sticklebacks. Nature, 484(7392), 55-61.

Junier, T., \& Zdobnov, E. M. (2010). The Newick utilities: high-throughput phylogenetic tree processing in the UNIX shell. Bioinformatics, 26(13), 1669-1670.

Katoh, K., Misawa, K., Kuma, K. I., \& Miyata, T. (2002). MAFFT: a novel method for rapid multiple sequence alignment based on fast Fourier transform. Nucleic acids research, 30, 3059-3066.

Kearse, M., Moir, R., Wilson, A., Stones-Havas, S., Cheung, M., Sturrock, S., ... \& Drummond, A. (2012). Geneious Basic: an integrated and extendable desktop software platform for the organization and analysis of sequence data. Bioinformatics, 28, 1647-1649.

Keir, A. F., \& Vogler, W. D. (2006). A review of current knowledge of the weedy species Themeda quadrivalvis (grader grass). Tropical Grasslands, 40(4), 193.

Kershaw, P., Moss, P., \& Van Der Kaars, S. (2003). Causes and consequences of long-term climatic variability on the Australian continent. Freshwater Biology, 48(7), 1274-1283.

Korneliussen, T. S., Albrechtsen, A., \& Nielsen, R. (2014). ANGSD: analysis of next generation sequencing data. BMC bioinformatics, 15, 1-13. 
Langmead, B., \& Salzberg, S. L. (2012). Fast gapped-read alignment with Bowtie 2. Nature methods, 9(4), 357-359.

Lefort, V., Longueville, J. E., \& Gascuel, O. (2017). SMS: smart model selection in PhyML. Molecular biology and evolution, 34, 2422-2424.

Li, H., Handsaker, B., Wysoker, A., Fennell, T., Ruan, J., Homer, N., ... \& Durbin, R. (2009). The sequence alignment/map format and SAMtools. Bioinformatics, 25(16), 2078-2079.

McCormick, R. F., Truong, S. K., Sreedasyam, A., Jenkins, J., Shu, S., Sims, D., ... \& Mullet, J. E. (2018). The Sorghum bicolor reference genome: improved assembly, gene annotations, a transcriptome atlas, and signatures of genome organization. The Plant Journal, 93, 338-354.

Meisner, J., \& Albrechtsen, A. (2018). Inferring population structure and admixture proportions in low-depth NGS data. Genetics, 210, 719-731.

Nguyen, L. T., Schmidt, H. A., Von Haeseler, A., \& Minh, B. Q. (2015). IQ-TREE: a fast and effective stochastic algorithm for estimating maximum-likelihood phylogenies. Molecular biology and evolution, 32(1), 268-274.

Nosil, P. (2012). Ecological speciation. Oxford University Press.

Olofsson, J. K., Bianconi, M., Besnard, G., Dunning, L. T., Lundgren, M. R., Holota, H., ... \& Christin, P. A. (2016). Genome biogeography reveals the intraspecific spread of adaptive mutations for a complex trait. Molecular ecology, 25(24), 6107-6123.

Ostevik, K. L., Moyers, B. T., Owens, G. L., \& Rieseberg, L. H. (2012). Parallel ecological speciation in plants?. International Journal of Ecology, 2012.

Olofsson, J. K., Cantera, I., Van de Paer, C., Hong-Wa, C., Zedane, L., Dunning, L. T., ... \& Besnard, G. (2019). Phylogenomics using low-depth whole genome sequencing: A case study with the olive tribe. Molecular ecology resources, 19, 877-892. 
Olofsson, J. K., Curran, E. V., Nyirenda, F., Bianconi, M. E., Dunning, L. T., Milenkovic, V., ... \& Christin, P. A. (2021). Low dispersal and ploidy differences in a grass maintain photosynthetic diversity despite gene flow and habitat overlap. Molecular Ecology, 30(9), 2116-2130.

Papadopulos, A. S., Helmstetter, A. J., Osborne, O., Comeault, A., Wood, D., Straw, E. A., ... \& Lighten, J. (2021). Rapid Parallel Adaptation to Anthropogenic Heavy Metal Pollution. Molecular Biology and Evolution.

Paradis, E., \& Schliep, K. (2019). ape 5.0: an environment for modern phylogenetics and evolutionary analyses in R. Bioinformatics, 35, 526-528.

Patel, R. K., \& Jain, M. (2012). NGS QC Toolkit: a toolkit for quality control of next generation sequencing data. PloS one, 7, e30619.

Pennington, R. T., \& Lavin, M. (2016). The contrasting nature of woody plant species in different neotropical forest biomes reflects differences in ecological stability. New Phytologist, 210(1), 25-37.

Kopelman, N. M., Mayzel, J., Jakobsson, M., Rosenberg, N. A., \& Mayrose, I. (2015). Clumpak: a program for identifying clustering modes and packaging population structure inferences across K. Molecular ecology resources, 15, 1179-1191.

Ruiz-Nieto, J. E., Aguirre-Mancilla, C. L., Acosta-Gallegos, J. A., Raya-Pérez, J. C., Piedra-lbarra, E., Vázquez-Medrano, J., \& Montero-Tavera, V. (2015). Photosynthesis and chloroplast genes are involved in water-use efficiency in common bean. Plant Physiology and Biochemistry, 86, 166-173.

Sage, R. F. (2017). A portrait of the C4 photosynthetic family on the 50th anniversary of its discovery: species number, evolutionary lineages, and Hall of Fame. Journal of experimental botany, 68(2), e11-e28.

Schmieder, R., \& Edwards, R. (2011). Quality control and preprocessing of metagenomic datasets. Bioinformatics, 27, 863-864. 
Simão, F. A., Waterhouse, R. M., loannidis, P., Kriventseva, E. V., \& Zdobnov, E. M. (2015). BUSCO: assessing genome assembly and annotation completeness with single-copy orthologs. Bioinformatics, 31(19), 3210-3212.

Skotte, L., Korneliussen, T. S., \& Albrechtsen, A. (2013). Estimating individual admixture proportions from next generation sequencing data. Genetics, 195, 693-702.

Smith, S. A., Moore, M. J., Brown, J. W., \& Yang, Y. (2015). Analysis of phylogenomic datasets reveals conflict, concordance, and gene duplications with examples from animals and plants. BMC evolutionary biology, 15(1), 1-15.

Soraggi, S., Rhodes, J., Altinkaya, I., Tarrant, O., Balloux, F., Fisher, M. C., \& Fumagalli, M. (2021). HMMploidy: inference of ploidy levels from short-read sequencing data. bioRxiv.

Snyman, H. A., Ingram, L. J., \& Kirkman, K. P. (2013). Themeda triandra: a keystone grass species. African Journal of Range \& Forage Science, 30(3), 99-125.

Stamp, M. A., \& Hadfield, J. D. (2020). The relative importance of plasticity versus genetic differentiation in explaining between population differences; a meta-analysis. Ecology letters, 23(10), 1432-1441.

Veldkamp, J. F. (2016). A revision of Themeda (Gramineae) in Malesia with a new species from Laos. Blumea-Biodiversity, Evolution and Biogeography of Plants, 61(1), 29-40.

Via, S., \& Lande, R. (1985). Genotype-environment interaction and the evolution of phenotypic plasticity. Evolution, 39(3), 505-522.

Yang, Z. (2007). PAML 4: phylogenetic analysis by maximum likelihood. Molecular biology and evolution, 24(8), 1586-1591.

Yang, Z., \& Nielsen, R. (2000). Estimating synonymous and nonsynonymous substitution rates under realistic evolutionary models. Molecular biology and evolution, 17(1), 32-43. 
bioRxiv preprint doi: https://doi.org/10.1101/2021.10.21.465284; this version posted October $22,2021$. The copyright holder for this

preprint (which was not certified by peer review) is the author/funder, who has granted bioRxiv a license to display the preprint in perpetuity. It is made available under aCC-BY-NC-ND 4.0 International license.

Zhang, C., Rabiee, M., Sayyari, E., \& Mirarab, S. (2018). ASTRAL-III: polynomial time species tree reconstruction from partially resolved gene trees. BMC bioinformatics, $19,15-30$. 


\section{[7] Data Accessibility}

All raw whole-genome sequencing data has been deposited in the NCBI Sequence Read Archive (Bioproject $X X X X$ ). Chloroplast genomes were submitted to NCBI GenBank

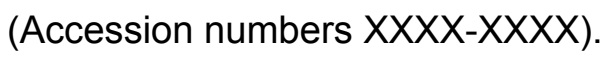




\section{[8] Author Contributions}

L.T.D and R.J conceived and designed the research with contributions from all coauthors.

P.C.B, S.N, N.B and R.J conducted fieldwork and generated initial ITS/ETS data. L.T.D,

J.K.O and A.S.T.P analysed the whole-genome data. L.T.D. and R.J. wrote the manuscript and all authors commented on the final version. 


\section{[9] Tables and Figures}

Figure 1: Phylogenetic relationships of Themeda inferred from whole chloroplast genomes.

The maximum likelihood topology inferred with the $G T R+I+G$ substitution model is shown with bootstrap support values. The sampling location of T. triandra accession in Australia Clade I and II is shown, and truncated branches are indicated. For samples not assigned to a clade a three letter abbreviation is used (THA = Thailand; TAN = Tanzania; CHN = China; AUS = Australia) .

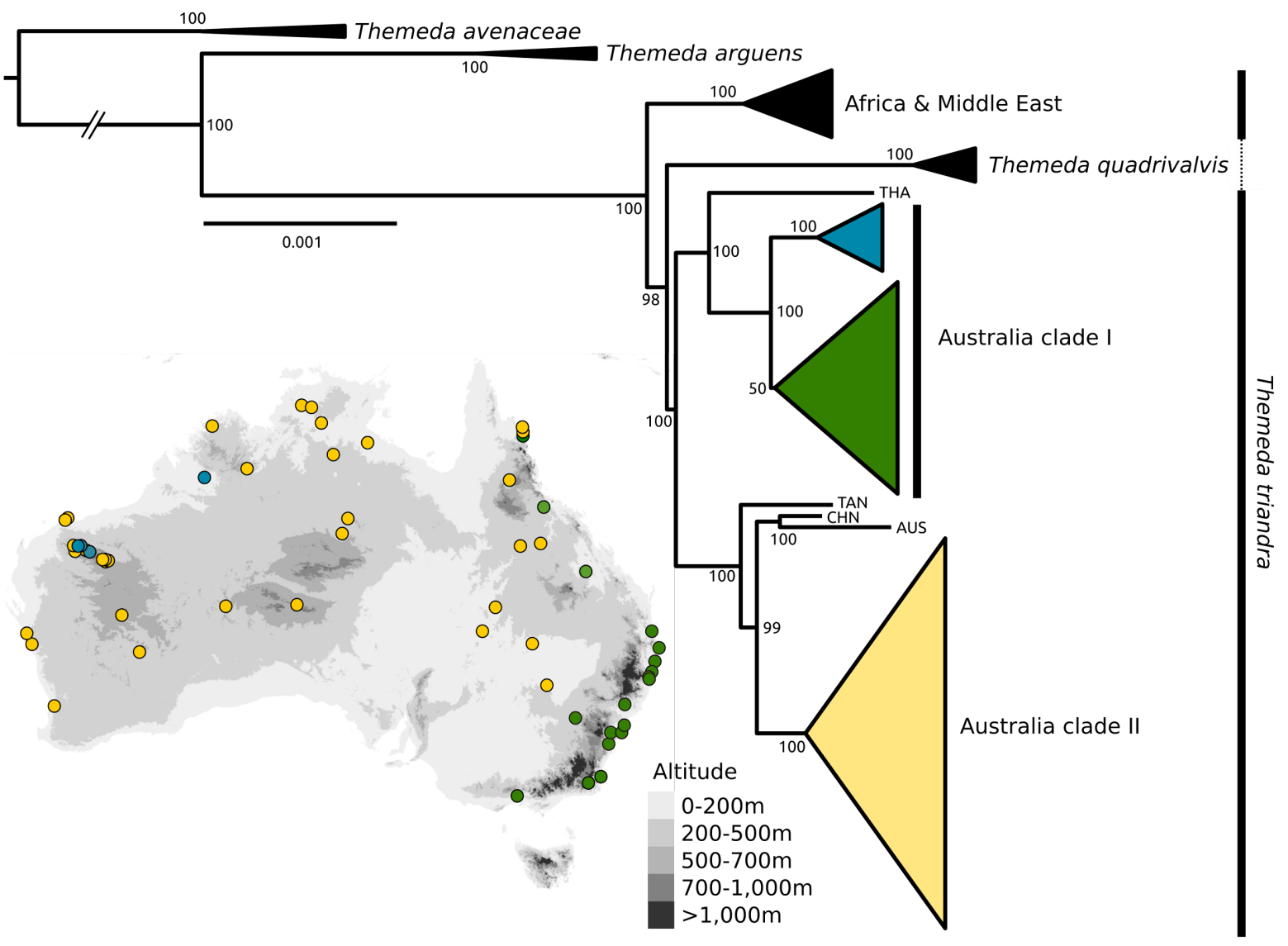


bioRxiv preprint doi: https://doi.org/10.1101/2021.10.21.465284; this version posted October 22,2021 . The copyright holder for this preprint (which was not certified by peer review) is the author/funder, who has granted bioRxiv a license to display the preprint in perpetuity. It is made available under aCC-BY-NC-ND 4.0 International license.

Figure 2: Phylogenetic relationships of Themeda inferred from 1,286 nuclear genes. A shows a maximum likelihood topology from a concatenated alignment of all loci with colours of the Australian clades based on chloroplast groupings (Figure 1). Bootstrap support values for the concatenated maximum likelihood tree are shown, followed by local posterior probabilities from a coalescence species tree for the same nuclear loci. The pie charts on key nodes represent the individual gene tree support for the topology shown. B shows a densitree plot of overlaid nuclear gene trees. Colours match the chloroplast clades, and truncated branches are indicated.

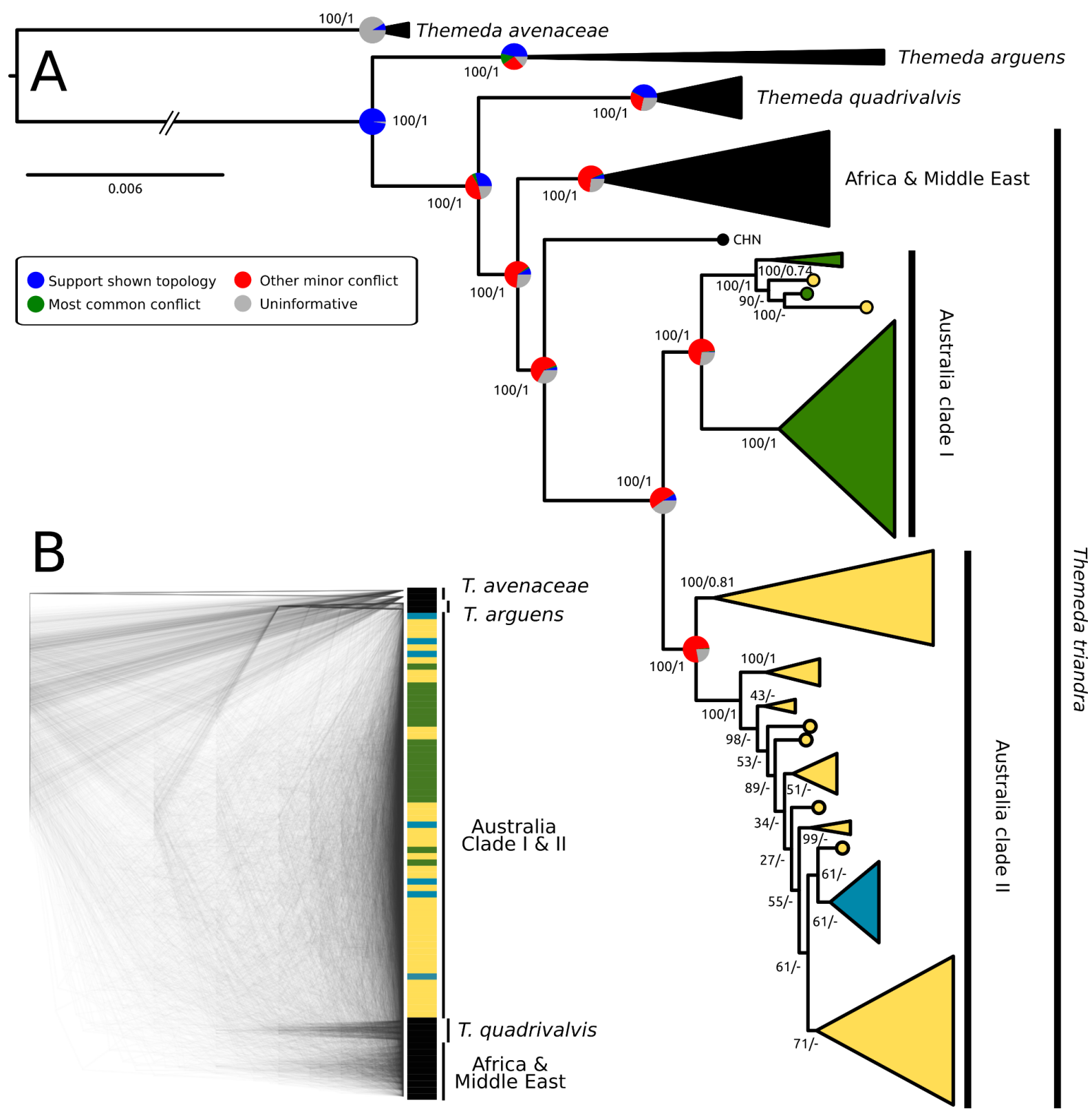


bioRxiv preprint doi: https://doi.org/10.1101/2021.10.21.465284; this version posted October $22,2021$. The copyright holder for this preprint (which was not certified by peer review) is the author/funder, who has granted bioRxiv a license to display the preprint in perpetuity. It is made available under aCC-BY-NC-ND 4.0 International license.

Figure 3: Genetic variation and structure within Themeda. (A) A principle component analysis across the first two axes is shown, with genetic groups coloured based on the chloroplast phylogeny as in Figure 1. (B) The mean likelihood and standard error for a range of $K S$ is shown, with these values used to calculate $\Delta K(C)$ as in Evanno et al., (2005). The assignment to genetic clusters is shown for two values of $K$. Samples are arranged within their chloroplast clade (indicated by that bar underneath the admixture plots), and ordered from west to east within each group. The asterisks indicate samples with a high degree of admixture.
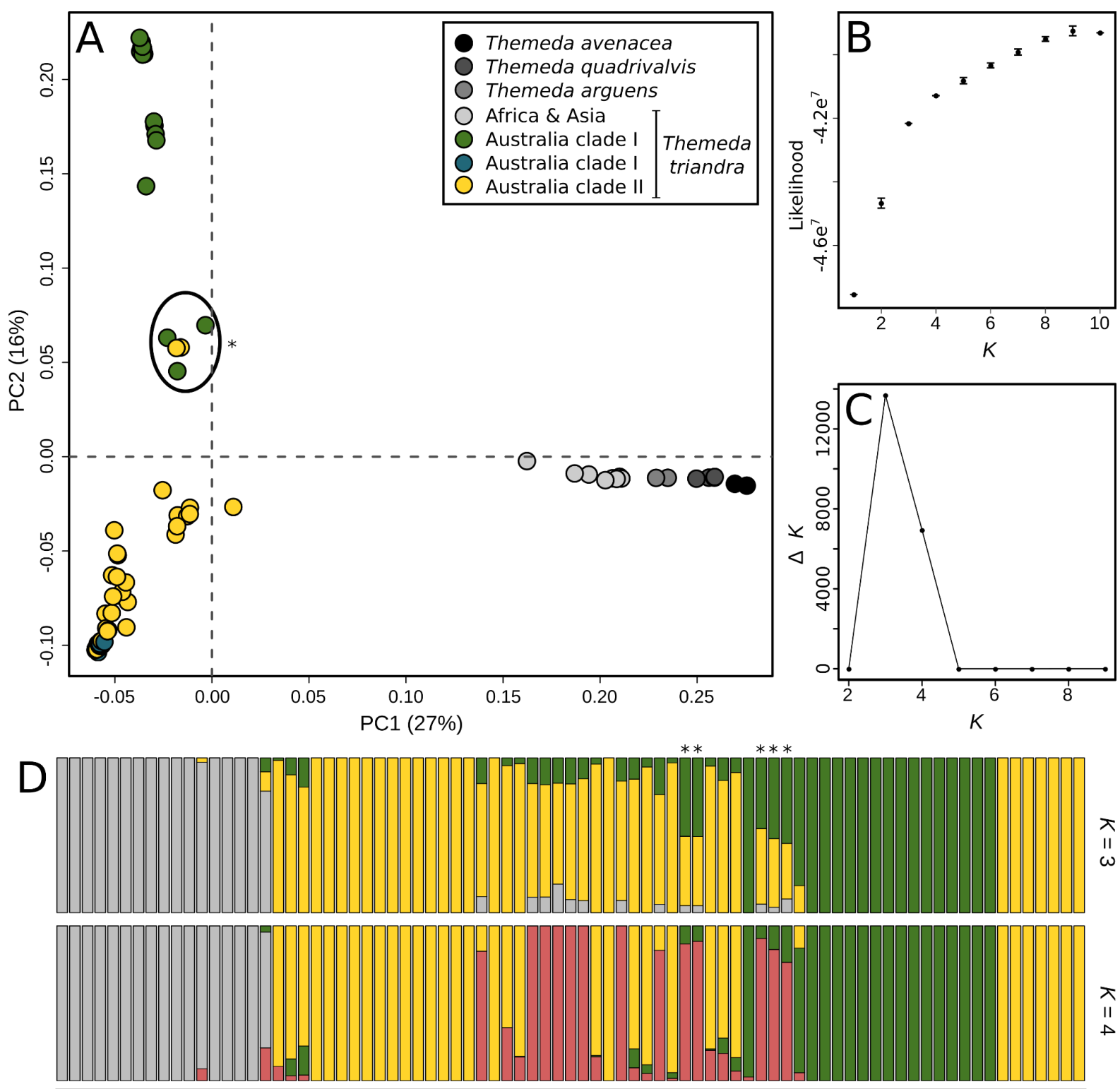


\section{[9] Supplementary Tables and Figures}

Table S1: Sample details:

Available from here:

https://docs.google.com/spreadsheets/d/1UcJz1HDWF8r2hDwboRzetbAbp SG0ZUm/edit?u sp=sharing \&ouid $=114024510845369830312 \&$ rtpof $=$ true $\& s d=$ true

Table S2: Inferring ploidy level results. Samples are ordered as they are in the nuclear phylogeny (Figure S3):

Available from here:

https://docs.google.com/spreadsheets/d/1BzZySUNc3SBSi-MXWo0uSinBeRS6GhjR/edit?us $\mathrm{p}=$ sharing\&ouid $=114024510845369830312 \&$ rtpof=true $\& \mathrm{sd}=$ true

Table S3: Results of the branch-site models used to detect positive selection. See figure S2 for the topology referred to.

\begin{tabular}{|l|l|l|l|}
\hline Model & Likelihood & P-value & Daughter Clade \\
\hline Null model & -6772.90 & - & - \\
\hline Branch 1 & -6772.90 & $1.00 \mathrm{E}+00$ & Claypan clade \\
\hline Branch 2 & -6772.23 & $2.49 \mathrm{E}-01$ & Australian Clade I \\
\hline Branch 3 & -6772.90 & $1.00 \mathrm{E}+00$ & Australian Clade I + Thailand \\
\hline Branch 4 & -6772.22 & $2.45 \mathrm{E}-01$ & Australian Clade II \\
\hline Branch 5 & -6772.90 & $1.00 \mathrm{E}+00$ & Australian Clade II + China \\
\hline Branch 6 & -6772.26 & $2.57 \mathrm{E}-01$ & Australian Clade II + China + Tanzania \\
\hline
\end{tabular}


bioRxiv preprint doi: https://doi.org/10.1101/2021.10.21.465284; this version posted October 22, 2021. The copyright holder for this preprint (which was not certified by peer review) is the author/funder, who has granted bioRxiv a license to display the preprint in perpetuity. It is made available under aCC-BY-NC-ND 4.0 International license.

Figure S1: Initial survey of Themeda diversity in Australia. (a) A maximum parsimony topology is inferred from the ITS/ETS barcode region for 332 accession. A subset of 67 accessions were subsequently selected for whole genome resequencing to ensure the diversity of Australian genotypes was sampled. (b) the geographic distribution of Australian samples is shown.

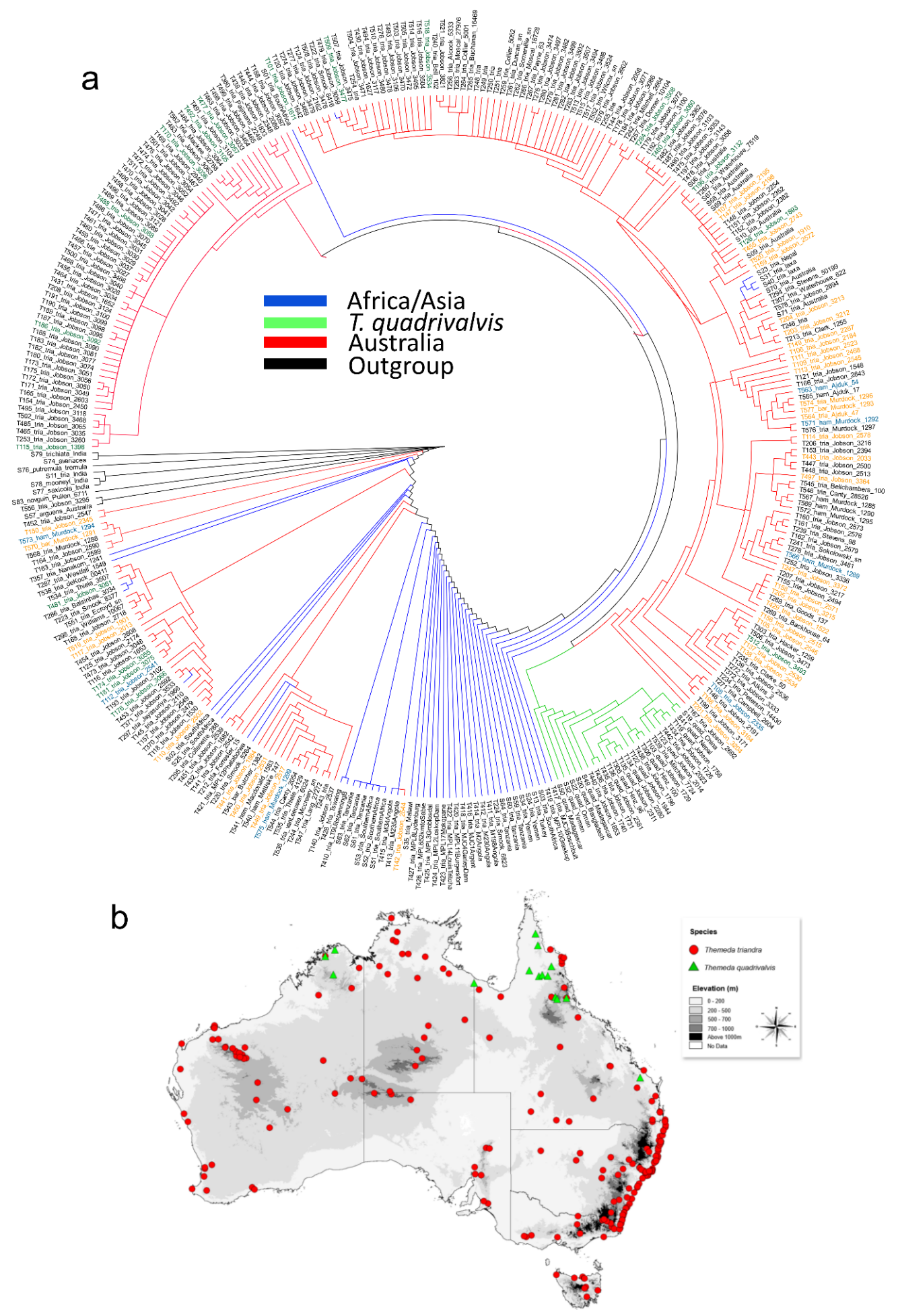


bioRxiv preprint doi: https://doi.org/10.1101/2021.10.21.465284; this version posted October 22, 2021. The copyright holder for this preprint (which was not certified by peer review) is the author/funder, who has granted bioRxiv a license to display the preprint in perpetuity. It is made available under aCC-BY-NC-ND 4.0 International license.

Figure S2: Phylogenetic relationships of Themeda inferred from whole chloroplast genomes. The maximum likelihood topology is shown with bootstrap support values based on 100 bootstrap replicates

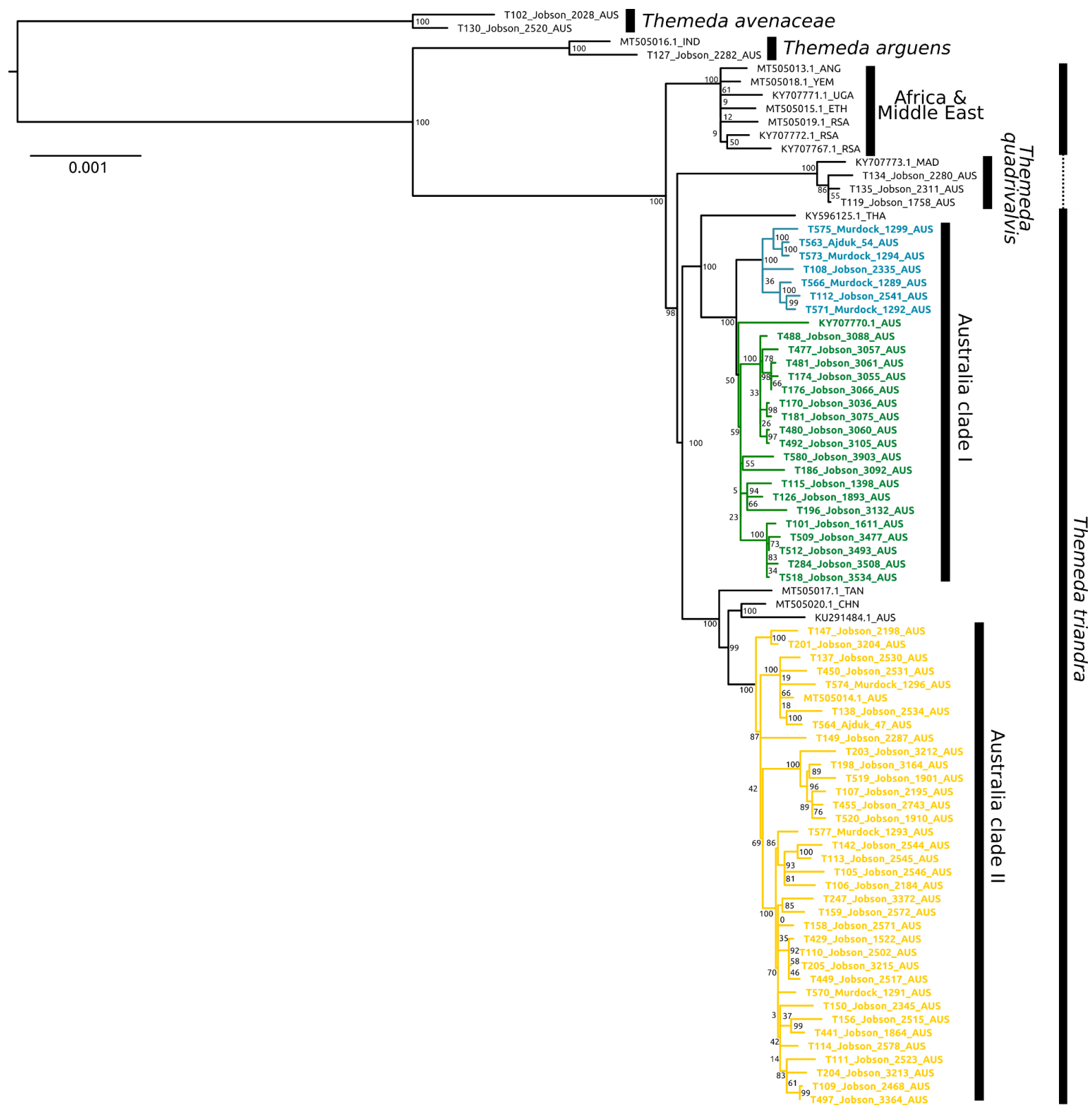


bioRxiv preprint doi: https://doi.org/10.1101/2021.10.21.465284; this version posted October 22, 2021. The copyright holder for this preprint (which was not certified by peer review) is the author/funder, who has granted bioRxiv a license to display the preprint in perpetuity. It is made available under aCC-BY-NC-ND 4.0 International license.

Figure S3: Phylogenetic relationships of Themeda inferred from a concatenated nuclear alignment of 1,286 genes. The maximum likelihood topology is shown with bootstrap support values based on 1,000 rapid bootstrap replicates. Colours are based on chloroplast clade.

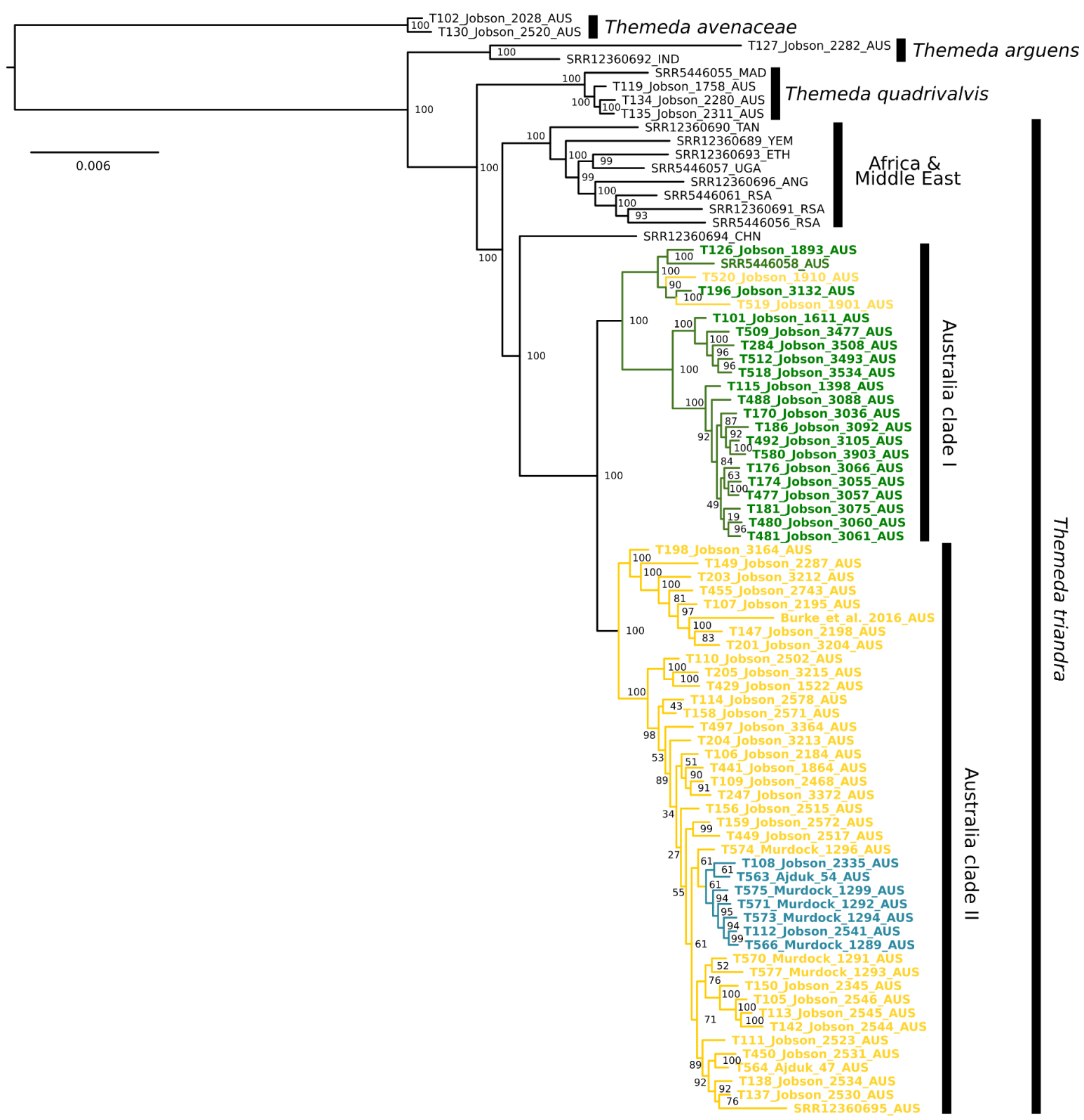


bioRxiv preprint doi: https://doi.org/10.1101/2021.10.21.465284; this version posted October 22, 2021. The copyright holder for this preprint (which was not certified by peer review) is the author/funder, who has granted bioRxiv a license to display the preprint in perpetuity. It is made available under aCC-BY-NC-ND 4.0 International license.

Figure S4: Phylogenetic relationships of Themeda inferred from 1,286 genes. The coalescence species tree is shown with local posterior probabilities. Branch lengths are in coalescence units, arbitrarily set to one for the tips. Colours are based on chloroplast clade.

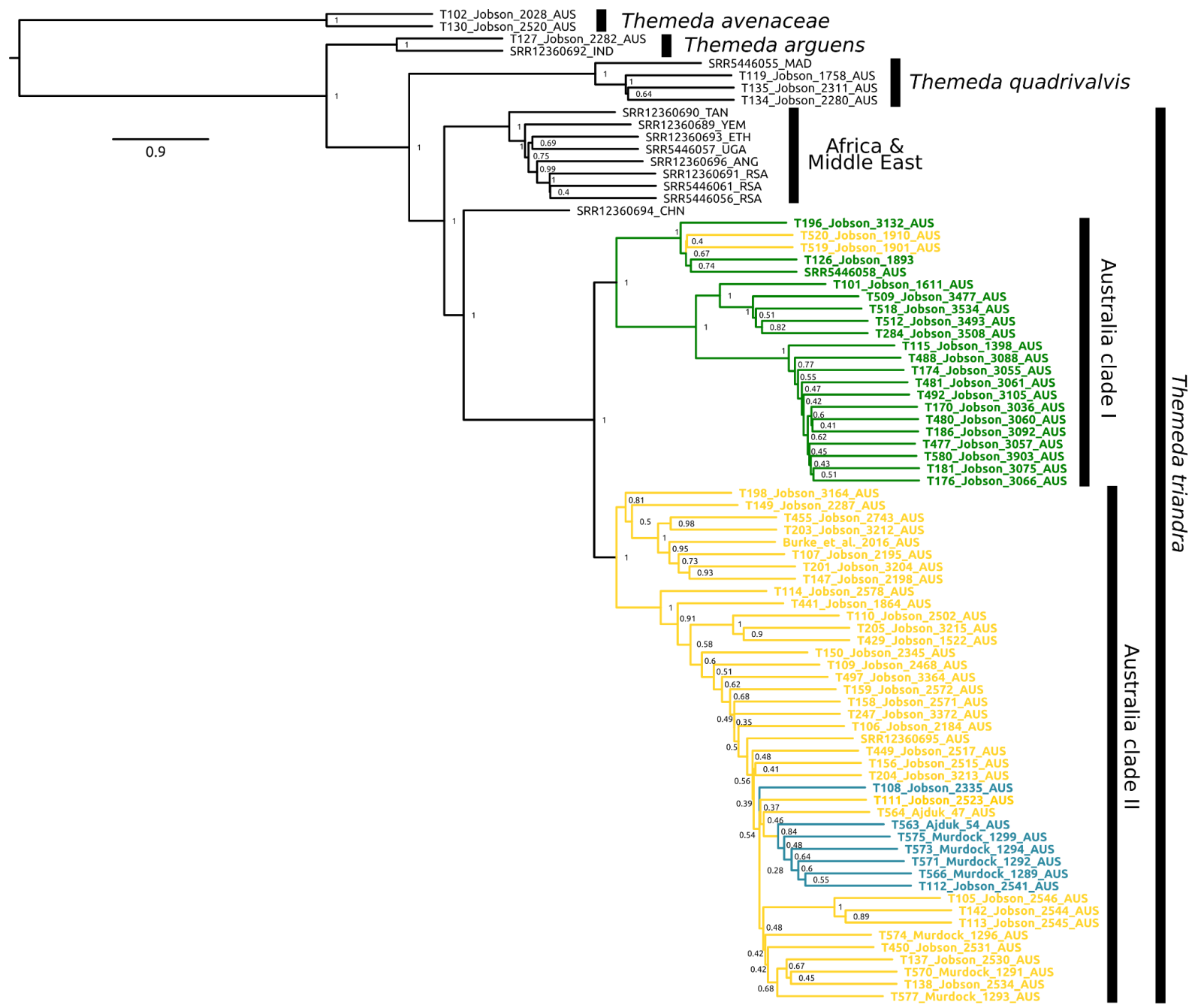


bioRxiv preprint doi: https://doi.org/10.1101/2021.10.21.465284; this version posted October 22,2021 . The copyright holder for this preprint (which was not certified by peer review) is the author/funder, who has granted bioRxiv a license to display the preprint in perpetuity. It is made available under aCC-BY-NC-ND 4.0 International license.

Figure S5: Evaluating individual gene tree support for the coalescence species tree topology. Branch lengths are arbitrary. Colours are based on chloroplast clade.

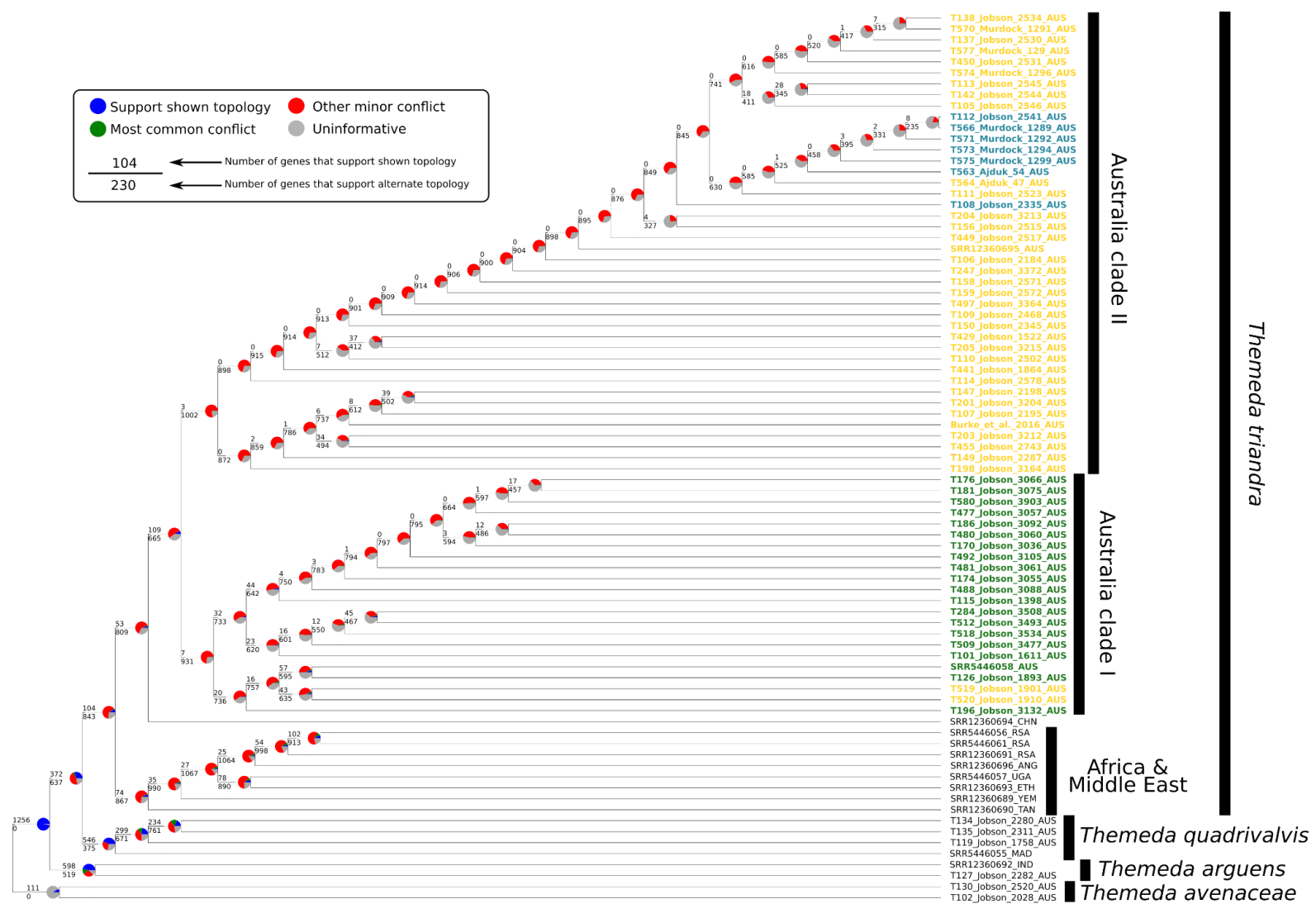


bioRxiv preprint doi: https://doi.org/10.1101/2021.10.21.465284; this version posted October 22, 2021. The copyright holder for this preprint (which was not certified by peer review) is the author/funder, who has granted bioRxiv a license to display the preprint in perpetuity. It is made available under aCC-BY-NC-ND 4.0 International license.

Figure S6: Genetic variation and structure within Themeda triandra in Australia. (A) A principle component analysis across the first two axes is shown, with genetic groups coloured based on the chloroplast phylogeny as in Figure 1. (B) The mean likelihood and standard error for a range of $K$ 's is shown, with these values used to calculate $\Delta K(C)$ as in Evanno et al., (2005). The assignment to genetic clusters is shown for two values of $K$. Samples are arranged within their chloroplast clade (indicated by that bar underneath the admixture plots), and ordered from west to east within each group. The asterisks indicate samples with a high degree of admixture.
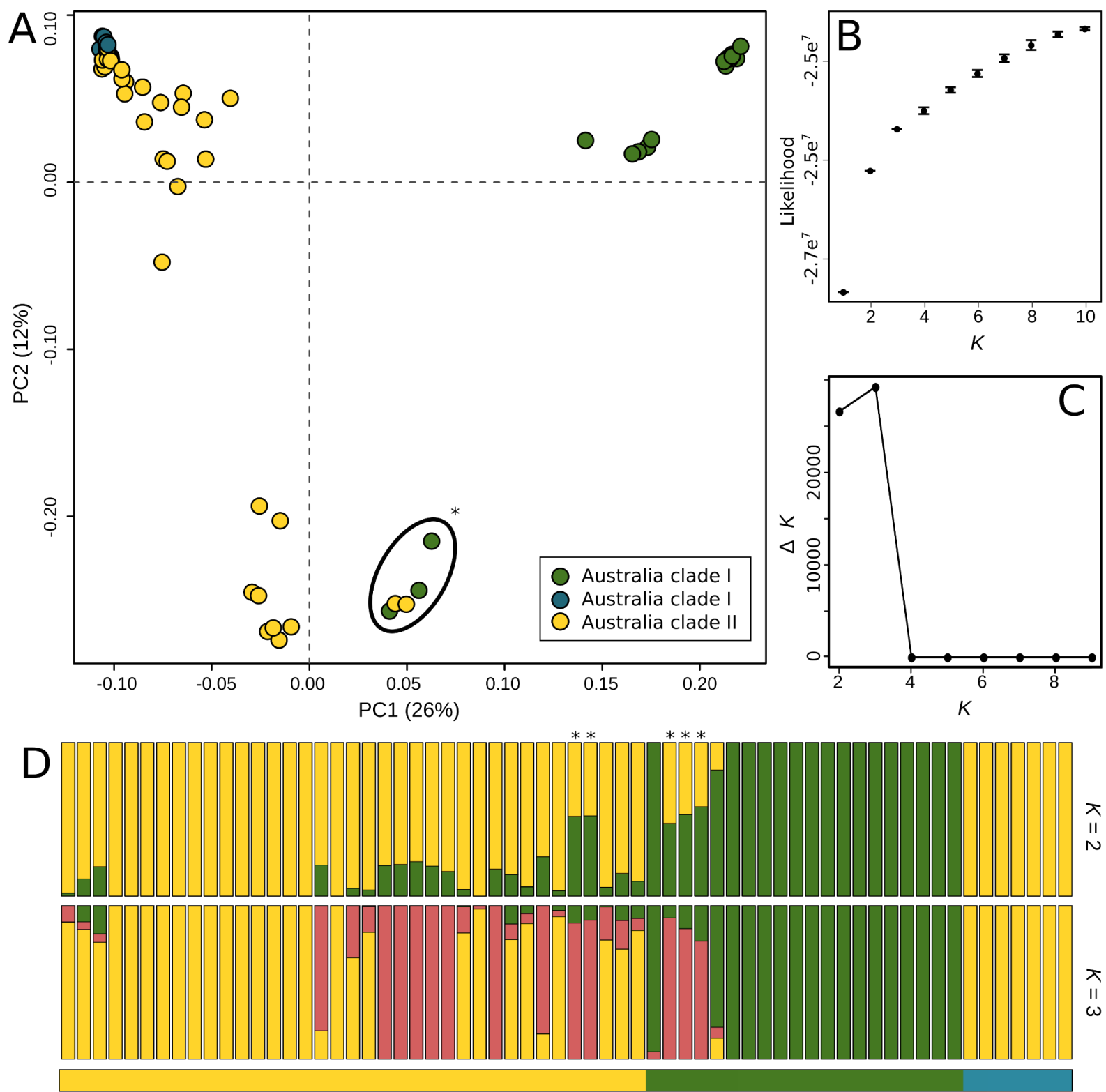
bioRxiv preprint doi: https://doi.org/10.1101/2021.10.21.465284; this version posted October 22,2021 . The copyright holder for this preprint (which was not certified by peer review) is the author/funder, who has granted bioRxiv a license to display the preprint in perpetuity. It is made available under aCC-BY-NC-ND 4.0 International license.

Figure S7: Violin plot of $F_{S T}$ between Australian Themeda triandra clades. $F_{S T}$ values were calculated across the genome in $50 \mathrm{~kb}$ windows (10kb slide), and the man value and standard are shown. The first two plots in the box represent the coastal ecotype against the claypan (blue) and inland (yellow) form respectively. The grey plot represents the inland ecotype compared to the claypan form.

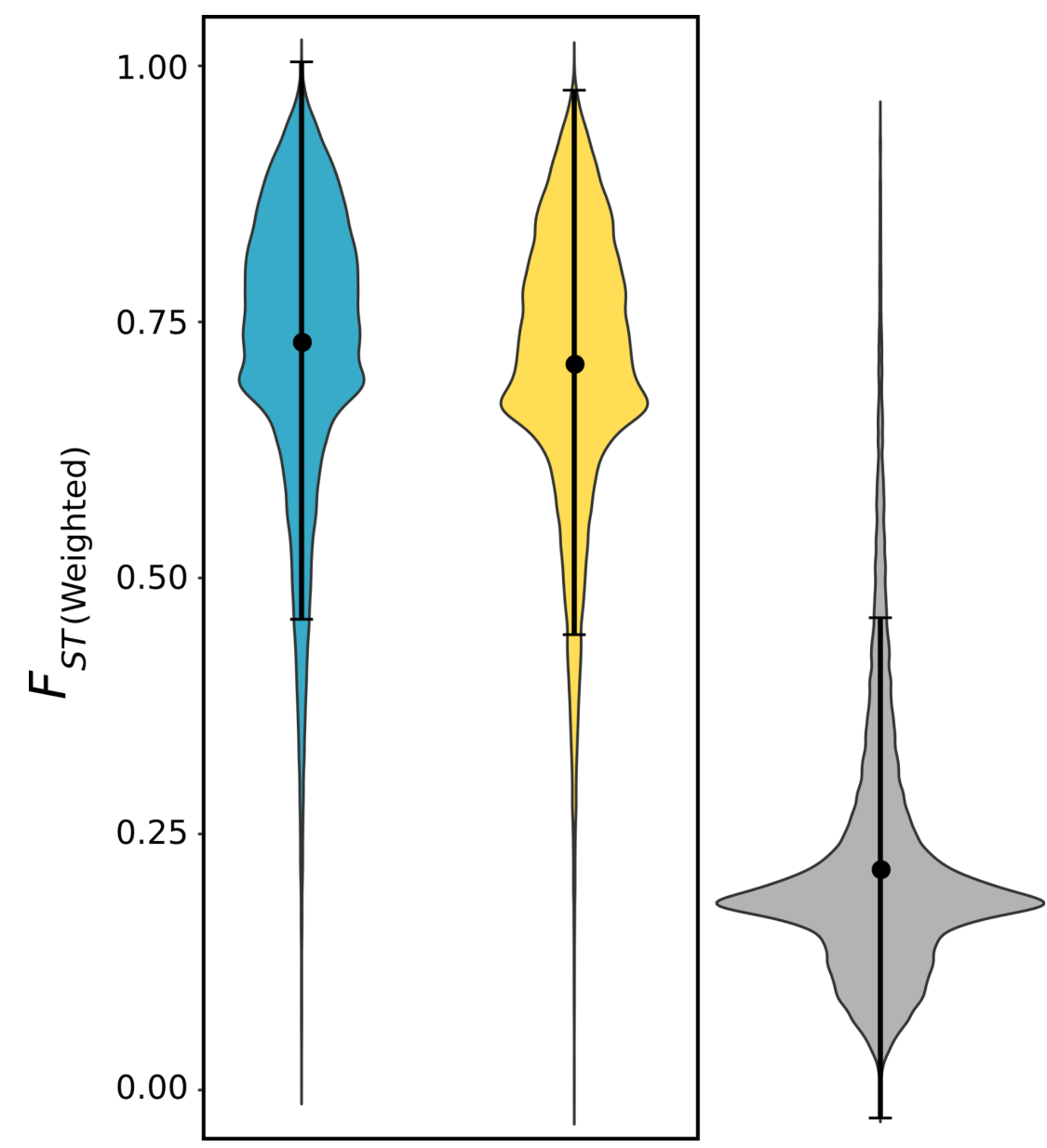

